\title{
Crystallization behavior of r.f.-sputtered TiNi thin films
}

\author{
J.Z. Chen, S.K. Wu* \\ Institute of Materials Science and Engineering, National Taiwan University, Taipei 106, Taiwan
}

Received 24 February 1998; accepted 14 August 1998

\begin{abstract}
Amorphous thin films of $\mathrm{Ti}_{45.6} \mathrm{Ni}_{54.4}$ and $\mathrm{Ti}_{50.4} \mathrm{Ni}_{49.6}$ alloys were deposited onto 3 inch diameter n-type (100)Si wafer by r.f. magnetron sputtering. The activation energy from an amorphous state to crystallization of the $\mathrm{Ti}_{45.6} \mathrm{Ni}_{54.4}$ free-standing thin film was found to be $385 \mathrm{~kJ}$ $\mathrm{mol}^{-1}$ by Avrami's method and $374 \mathrm{~kJ} \mathrm{~mol}^{-1}$ by Kissinger's method. The values of Avrami exponents are 2.56, 2.65, 2.7, and 3 for isothermal annealing temperatures of $527,532,542$, and $547^{\circ} \mathrm{C}$ respectively. The activation energy for the crystallization process of $\mathrm{Ti}_{50.4} \mathrm{Ni}_{49.6}$ film-on-substrate is estimated as $287.6 \mathrm{~kJ} \mathrm{~mol}^{-1}$ from X-ray diffraction experiment. This value is much smaller than those from Avrami's or Kissinger's methods owing to the effects of the residual compression stress on the thin film and the volume reduction after crystallization. (C) 1999 Elsevier Science S.A. All rights reserved.
\end{abstract}

Keywords: Amorphous materials; Annealing; Crystallization; Sputtering

\section{Introduction}

The equiatomic TiNi alloy is known as a shape memory alloy (SMA) because it exhibits the shape memory effect (SME) and superelasticity (PE) [1]. However, amorphous TiNi material does not behave as a shape memory alloy. It is well known that as-sputtered TiNi thin film deposited onto a non-artificial heated substrate is amorphous [2]. Therefore, the crystallization behavior, such as the crystallization temperature and its activation energy, is very important for the fabrication process of TiNi thin films.

The crystallization behavior of amorphous TiNi material has been reported in several articles [3-5]. However, the samples used were all bulk material, not thin films, and the compositions of the samples were all very dissimilar to the equiatomic TiNi shape memory alloy. Therefore, these reported data are not appropriate for the practical fabrication of TiNi thin films. Moreover, TiNi thin film is usually regarded as a smart material and is applied in the field of MEMS (microelectronmechanical system) [6-9]. The films are fabricated primarily by micro-machining technology in which the film is usually less than $3 \mu \mathrm{m}$ in thickness and rarely peeled down from the substrate in the process. The substrate gives the film a constrained force and affects the crystallization behavior of the amorphous TiNi thin film.

In the present research, TiNi thin films with nearly equia-

\footnotetext{
* Corresponding author.
}

tomic compositions were studied. The films with a thickness of about $6-8 \mu \mathrm{m}$ were removed from the substrate and then tested by differential scanning calorimetry (DSC). Since the crystallization of the amorphous alloy is a highly exothermic process, the crystallization temperature can be measured directly from the DSC curve. From DSC data, the activation energy of crystallization can be calculated by both Kissinger's method [10] and Avrami's method [11-13]. Thus the crystallization temperature and activation energy of free-standing TiNi thin films can be successfully determined. Moreover, from the viewpoint of practical application, the TiNi thin films should be coated on a substrate and then directly subjected to an annealing process. Thus, the TiNi thin films with a thickness of about $1-2 \mu \mathrm{m}$ were not peeled from the substrate and their crystallization behavior was investigated using X-ray diffraction (XRD) data.

\section{Experimental details}

TiNi thin films were deposited onto a 3 inch diameter ntype (100)Si wafer in a 2 inch r.f. magnetron sputtering apparatus using a Ti-49.0 at.\% Ni target. The target was prepared by vacuum arc melting from the raw materials of titanium (purity 99.7 wt.\%) and nickel (purity 99.9 wt.\%), then hot rolled at $850^{\circ} \mathrm{C}$ to 0.125 inch thickness, and finally wire cut into a 2 inch diameter target disk. The sputtering conditions used in this study are given in Table 1; the substrate was not heated during the sputtering. Two types 
Table 1

Sputtering conditions used in this study and composition of the sputtered films

\begin{tabular}{|c|c|c|c|c|c|c|c|}
\hline \multirow[t]{2}{*}{$\begin{array}{l}\text { Type of } \\
\text { film }\end{array}$} & \multirow{2}{*}{$\begin{array}{l}\text { Argon gas } \\
\text { pressure } \\
\text { (Torr) }\end{array}$} & \multirow{2}{*}{$\begin{array}{l}\text { R.f. } \\
\text { power } \\
(\mathrm{W})\end{array}$} & \multirow{2}{*}{$\begin{array}{l}\text { Sputtered } \\
\text { film } \\
\text { thickness } \\
(\mu \mathrm{m})\end{array}$} & \multirow{2}{*}{$\begin{array}{l}\text { Distance } \\
\text { between target } \\
\text { and substrate } \\
(\mathrm{mm})\end{array}$} & \multirow[t]{2}{*}{$\begin{array}{l}\text { Sputtering } \\
\text { time (min) }\end{array}$} & \multicolumn{2}{|c|}{$\begin{array}{l}\text { Average composition } \\
\text { (at.\%) }\end{array}$} \\
\hline & & & & & & $\mathrm{Ti}$ & $\mathrm{Ni}$ \\
\hline A & 0.002 & 200 & $6-8$ & 50 & 180 & 45.6 & 54.4 \\
\hline B & 0.011 & 200 & $1-2$ & 80 & 30 & 50.4 & 49.6 \\
\hline
\end{tabular}

of thin film were r.f. sputtered. Film A is thick $(6-8 \mu \mathrm{m}$ thickness) and film $B$ is thin $(1-2 \mu \mathrm{m})$. The compositions of the thin sputtered films were determined by the electron probe microanalyzer (EPMA) of a JEOL JXA-8600SX instrument. The sputtered films were then annealed to crystalline form using several methods, as summarized in Table 2.

Films A were deposited at a greater thickness (around 6$8 \mu \mathrm{m}$ ) so that they could be peeled easily from the substrate. The peeled films were cut into smaller pieces and encapsulated in an aluminum pan for the DSC test. DSC measurement was conducted by a Dupont 2000 thermal analyzer equipped with a quantitative scanning system 910 DSC cell for controlled heating and cooling in pure Ar gas. In order to find the crystallization temperature of films A, some samples were heated by DSC from 100 to $570^{\circ} \mathrm{C}$ with a heating rate of $10^{\circ} \mathrm{C} \mathrm{min}^{-1}$ (method I). Some other samples were put directly into the $500^{\circ} \mathrm{C} \mathrm{DSC}$ cell and heated with a heating rate of $20^{\circ} \mathrm{C} \mathrm{min}^{-1}$ from $500^{\circ} \mathrm{C}$ to temperatures around the crystallization temperature, say 527, 532, 542 and $547^{\circ} \mathrm{C}$, and then kept isothermally until they were fully crystallized (method II). The results of DSC measurement of method II were used to calculate the activation energy of crystallization by Arvami's method [11-13]. On the other hand, Kissinger's method for calculating the activation energy of crystallization requires data of different heating rates in the DSC test, in which each heating rate corresponds to its crystallization peak temperature. Thus some other samples were heated in DSC from 450 to $570^{\circ} \mathrm{C}$ with different heating rates, say $5,10,20$ and $30^{\circ} \mathrm{C}$ $\min ^{-1}$ (method III).

Films B were deposited to a smaller thickness (around 1-

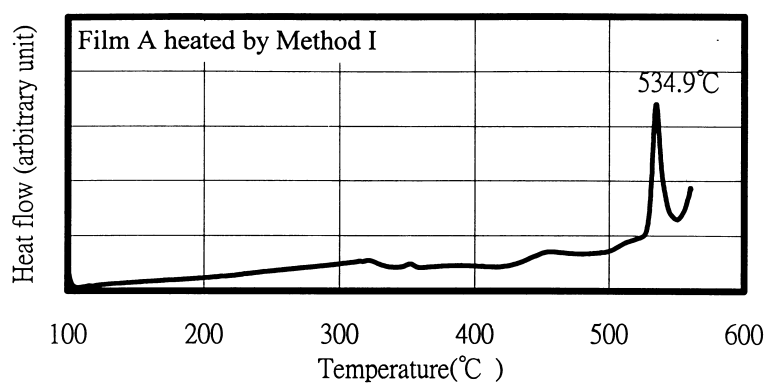

Fig. 1. The DSC curve of film A according to method I of Table 2.
$2 \mu \mathrm{m})$ and used to obtain the crystallization activation energy of film-on-substrate using XRD. Films B were isothermally annealed at $550,575,600$, and $625^{\circ} \mathrm{C}$ for various times in a rapid heating IR furnace (method IV). The heating rate of the IR furnace reaches $3000^{\circ} \mathrm{C} \mathrm{min}-1$ and the cooling rate is about $260^{\circ} \mathrm{C} \mathrm{min}^{-1}$ at $600^{\circ} \mathrm{C}$. Moreover, the IR furnace is able to control the annealing time to a precision of $0.1 \mathrm{~min}$. This feature provides good control of the annealing time for annealing samples of films B. The crystallization phases of annealed samples were confirmed by a Philips PW1719 XRD instrument.

\section{Results and discussion}

\subsection{Crystallization temperature of sputtered TiNi thin films}

Fig. 1 shows a sample of film A heated in DSC according to method I of Table 2 and crystallized with a single heat peak. The crystallization temperature, taken as the temperature at onset, is $534.9^{\circ} \mathrm{C}$.

\subsection{Avrami's method}

Fig. 2 is the DSC curve of a $542^{\circ} \mathrm{C}$ isothermally annealed sample heated according to method II of Table 2. In Fig. 2, the starting and finishing times of crystallizing transformation of the TiNi thin film are labeled A and B respectively. The DSC curves of other isothermal annealing temperatures used for method II are similar to those of Fig. 2 and thus are omitted. The transformed fraction, $x(t)$, up to any time $t$, is taken to be proportional to the fractional area under the peak up to this time [14]. The value of $x(t)$ can be calculated in each sampling time point and the results are plotted in Fig. 3. The curve of Fig. 3 is of the familiar sigmoidal type. Therefore the kinetics of the transformation can be analyzed in terms of the Avrami equation [11-13]:

$x(t)=1-\exp \left(-b t^{n}\right)$

where $b$ is a rate constant and $n$ is an exponent which need not be an integer.

Eq. (1) can be rearranged as the well known John-MehlAvrami equation:

$\ln (-\ln (1-x))=\ln (b)+n \ln (t)$ 
Table 2

Four methods used in this study to anneal the sputtered films

\begin{tabular}{|c|c|c|c|}
\hline Method & Details of annealing & $\begin{array}{l}\text { Composition and thickness } \\
\text { of sputtered films }\end{array}$ & Status of films before annealing \\
\hline $\begin{array}{l}\text { Method I (find the crystallization } \\
\text { temperature) }\end{array}$ & $\begin{array}{l}\text { Heated by DSC from } 100 \text { to } 570^{\circ} \mathrm{C} \text { with } \\
\text { a heating rate of } 10^{\circ} \mathrm{C} \mathrm{min} \text { min }^{-1}\end{array}$ & $\mathrm{Ti}_{45.6} \mathrm{Ni}_{54.4}, 6-8 \mu \mathrm{m}($ film A) & $\begin{array}{l}\text { Amorphous films removed from } \\
\text { the substrate }\end{array}$ \\
\hline Method II (Avrami's method) & $\begin{array}{l}\text { Heated by DSC from } 500^{\circ} \mathrm{C} \text { with a } \\
\text { heating rate of } 20^{\circ} \mathrm{C} \min ^{-1} \text { to } 527,532 \text {, } \\
542,547^{\circ} \mathrm{C} \text {, then kept isothermally until } \\
\text { the crystallization has finished }\end{array}$ & $\mathrm{Ti}_{45.6} \mathrm{Ni}_{54.4}, 6-8 \mu \mathrm{m}($ film $\mathrm{A})$ & $\begin{array}{l}\text { Amorphous films removed from } \\
\text { the substrate }\end{array}$ \\
\hline Method III (Kissinger's method) & $\begin{array}{l}\text { Heated by DSC from } 450 \text { to } 570^{\circ} \mathrm{C} \text { with } \\
\text { different heating rates of } 5,10,20,30^{\circ} \mathrm{C} \\
\mathrm{min}^{-1}\end{array}$ & $\mathrm{Ti}_{45.6} \mathrm{Ni}_{54.4}, 6-8 \mu \mathrm{m}($ film A) & $\begin{array}{l}\text { Amorphous films were removed } \\
\text { from the substrate }\end{array}$ \\
\hline Method IV (XRD experiments) & 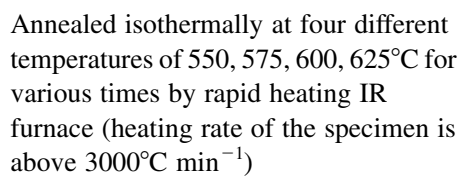 & $\mathrm{Ti}_{50.4} \mathrm{Ni}_{49.6}, 1-2 \mu \mathrm{m}($ film B) & $\begin{array}{l}\text { Amorphous films on the } \mathrm{Si} \\
\text { wafer substrate }\end{array}$ \\
\hline
\end{tabular}

Fig. 4 shows the plot of $\ln (-\ln (1-x))$ against $\ln (t)$ for each annealing temperature of Fig. 3. The plot approximates to straight lines in the mean part of $x(t)$. The values of the Avrami exponent $n$, given by the slope of the graphs in Fig. 4, are calculated and indicated in Table 3. Deviations from linearity for the small $x$ are thought to be due to the termination errors in Eq. (2), whereas at deviations from linearity for $x$ approaching 1 the grain growth of already crystallized material probably becomes significant [14].

From Table 3, the value of $n$, ranging from 2.56 to 3, tends to rise with increasing annealing temperature. The value of $n=3$ indicates that the sample nucleates only at the start of crystallization, while $n=2$ refers to a continuing nucleation at grain edges during transformation [15]. This suggests that the nucleation mechanisms of amorphous TiNi thin films are different under different isothermal annealing temperatures. From the trend in Table 3, i.e. the Avrami exponent $n$ increases as the isothermal annealing temperature increases, the nucleation mechanism of $n=3$ is more likely to dominate under the higher isothermal annealing temperature while the mechanism of $n=2$ tends to dominate under the lower annealing temperature. This conclusion

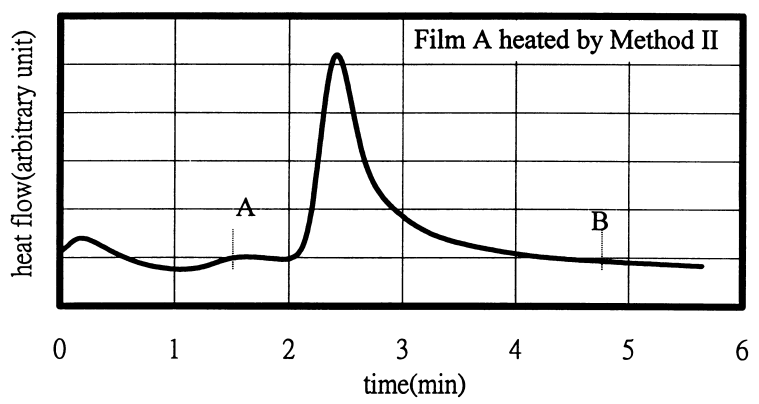

Fig. 2. The DSC curve for $542^{\circ} \mathrm{C}$ isothermal annealing of film A. Points A and $\mathrm{B}$ are the starting time and finishing time of the crystallization transformation. seems to be reasonable because the higher the annealing temperature, the more energy the atoms have. Thus more atoms of the amorphous TiNi thin film have the ability to overcome the activation energy barrier to nucleate and more nuclei can form at the beginning of transformation. This is the case of isothermal annealing at $547^{\circ} \mathrm{C}$ as shown in Fig. 4. On the contrary, at a lower annealing temperature, not so many atoms have the energy to overcome the activation energy barrier to nucleate at the beginning of crystallization. They can only nucleate during the crystallization process. Thus, at a lower isothermal annealing temperature, the crystallization mechanism is more likely to be the type indicated by the Avrami exponent $n=2$. The Avrami exponent in the case of $527^{\circ} \mathrm{C}$ annealing is 2.56 which deviates from the case of $547^{\circ} \mathrm{C}$ with the Avrami exponent $n=3$ and tends to approach to $n=2$. Any postulation as to the precise mechanism of the crystallization process, however, requires detailed microscopic evidence. A further study on the microstructure of the annealed TiNi thin films is being conducted now.

Activation energies for the results of Figs. 3 and 4 are deduced from the temperature dependence of the time $t$ to

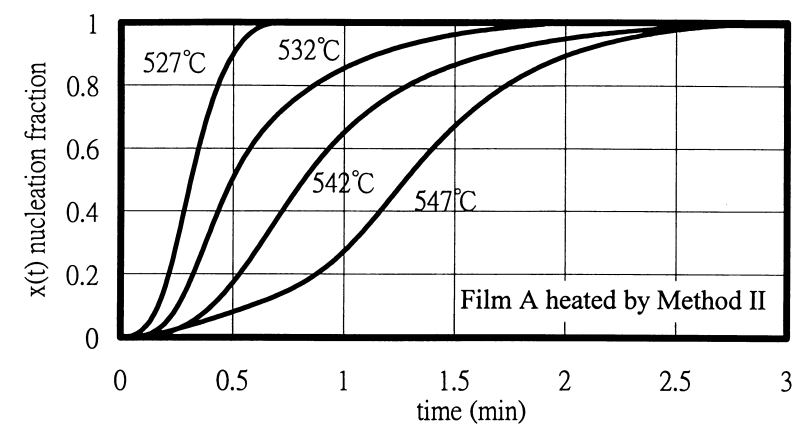

Fig. 3. Transformed fraction $x(t)$ as a function of time $t$ with annealing temperatures $527,532,542$ and $547^{\circ} \mathrm{C}$ for film A heated according to method II of Table 2. 


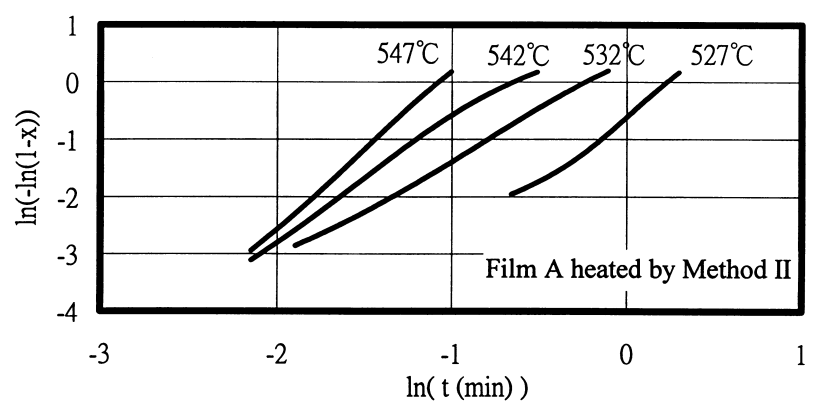

Fig. 4. Avrami plots for film A of Fig. 3.

$50 \%$ crystallization [14], i.e.

$t_{0.5}=A \exp (Q / R T)$

where $A$ is a constant, $Q$ is the activation energy, and $R$ the ideal gas constant.

Fig. 5 shows the plots of $\ln \left(t_{0.5}\right)$ against $1 / T$ of the data shown in Figs. 3 and 4. From Fig. 5, the activation energy of sputtered TiNi thin film A heated according to method II of Table 2 is determined to be $385 \mathrm{~kJ} \mathrm{~mol}^{-1}$.

\subsection{Kissinger's method}

The crystallization activation energy of amorphous thin films can also be calculated by Kissinger's method (method III of Table 2) according to the following equation:

$\ln \left(\alpha / T_{\mathrm{p}}^{2}\right)=C-Q / R T_{\mathrm{p}}$

where $\alpha$ is the heating rate, $T_{\mathrm{p}}$ is the peak temperature of the DSC curve, and $C$ is a constant.

Fig. 6 shows the DSC curves of specimens heated by method III of Table 2 with the peak temperatures and corresponding heating rates indicated. From the data of Fig. 6, $\ln \left(\alpha / T_{\mathrm{p}}^{2}\right)$ versus $1 / T_{\mathrm{p}}$ is plotted in Fig. 7 and the activation energy is determined to be $374 \mathrm{~kJ} \mathrm{~mol}^{-1}$. This result is quite close to that obtained by the Avrami method in Section 3.2.

Buschow [3] and Seeger and Ryder [5] have measured the activation energies of a series of binary $\mathrm{Ti}_{x} \mathrm{Ni}_{1-x}$ bulk amorphous alloys in DSC using the continuous heating of Kissinger's method. $\mathrm{Ti}_{x} \mathrm{Ni}_{1-x}$ samples with $x=0.76,0.70$, $0.60,0.42,0.38$ at. \% were studied by Buschow and samples with $x=0.70,0.66,0.60$ at.\% were studied by Seeger and Ryder. $\mathrm{Ti}_{70} \mathrm{Ni}_{30}$ and $\mathrm{Ti}_{60} \mathrm{Ni}_{40}$ samples were crystallized in two stages in Seeger's experiment. However, this twostage crystallizaion is not found in this study of $\mathrm{Ti}_{45.6} \mathrm{Ni}_{54.4}$ thin film. The crystallization activation energy of bulk $\mathrm{Ti}_{x} \mathrm{Ni}_{1-x}$ material from Buschow [3] is plotted as a function of the alloy composition in Fig. 8. The experimental results

Table 3

Values of Avrami exponent $n$ for different isothermal annealing temperatures of Fig. 4

\begin{tabular}{lllll}
\hline Temperature $\left({ }^{\circ} \mathrm{C}\right)$ & 527 & 532 & 542 & 547 \\
Avrami exponent $n$ & 2.56 & 2.65 & 2.7 & 3 \\
\hline
\end{tabular}

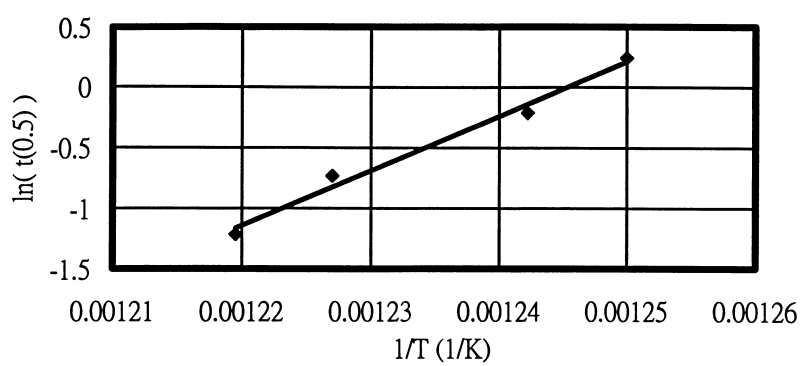

Fig. 5. Arrhenius plot for $50 \%$ crystallization time $\ln \left(t_{0.5}\right)$ versus $1 / T$ of the data of Figs. 3 and 4.

of $\mathrm{Ti}_{45.6} \mathrm{Ni}_{54.4}$ thin film according to Avrami and Kissinger's methods of this study are also labeled in Fig. 8. They are quite close to the Buschow curve, but the values are less than expected. We suggest that the TiNi sputtered thin films of this study are not entirely amorphous, but there were small nuclei present before annealing. Similarly, thin foils of TiNi SMA amorphized by high energy electron bombardment in a high voltage transmission electron microscope exhibit approximately $3 \mathrm{~nm}$ diameter crystalline nuclei inside according to observation by high resolution transmission electron microscopy [16].

\subsection{XRD experiment}

Samples of film B were annealed without peeling off from the silicon substrate according to method IV of Table 2. Fig. 9a shows the XRD experimental result of as-deposited amorphous film B. Figs. 9b,c are the XRD spectra of $550^{\circ} \mathrm{C}$ and $600^{\circ} \mathrm{C}$ isothermal annealing at different anneal times. The $44^{\circ}$ mound in Fig. 9a indicates the amorphous TiNi phase, while $42^{\circ}$ and $43.5^{\circ}$ peaks in Figs. 9 b,c refer to as-crystallized (110) $)_{\mathrm{TiNi} B}$ and (003) $)_{\mathrm{TiO} 2}$ respectively. As the

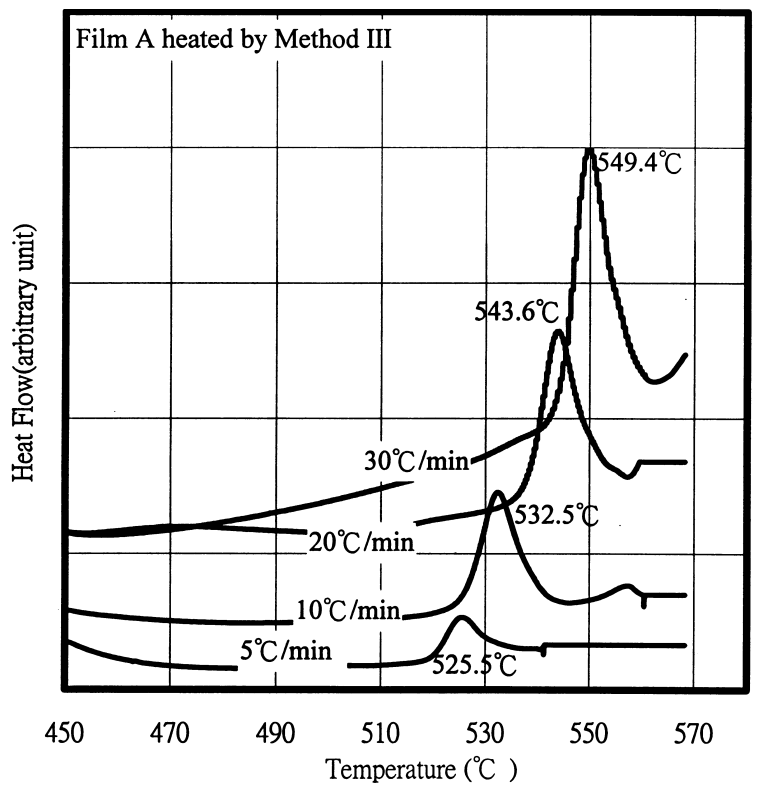

Fig. 6. DSC curve with different heating rates from 450 to $570^{\circ} \mathrm{C}$ for film A heated according to method III of Table 2. 


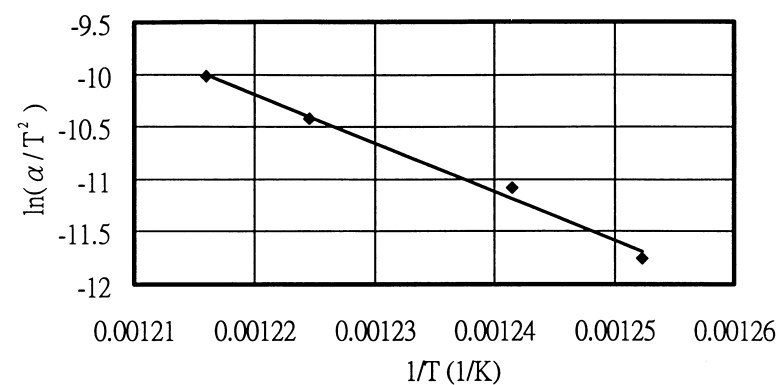

Fig. 7. Kissinger's plots for the DSC data of Fig. 6.

anneal time increases, the peak intensity of the TiNi B2 parent phase also increases along with the decrease in the TiNi amorphous $44^{\circ}$ mound.

The finish time of the amorphous-to-crystalline transformation can be defined as the time when the amorphous $44^{\circ}$ mound disappears. From this criterion, the finish time of

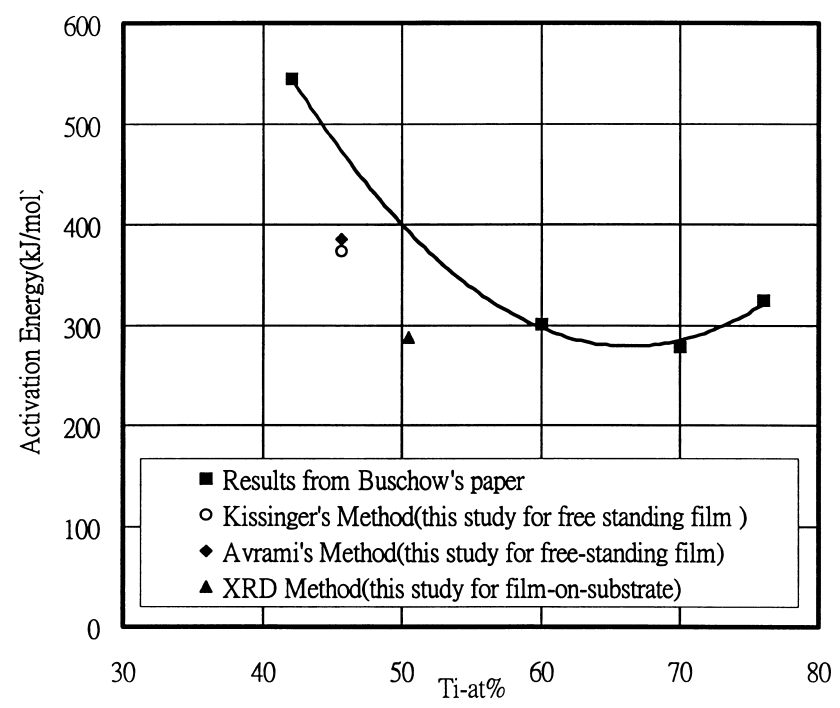

Fig. 8. Comparison of the result of Buschow [3] and of this paper.

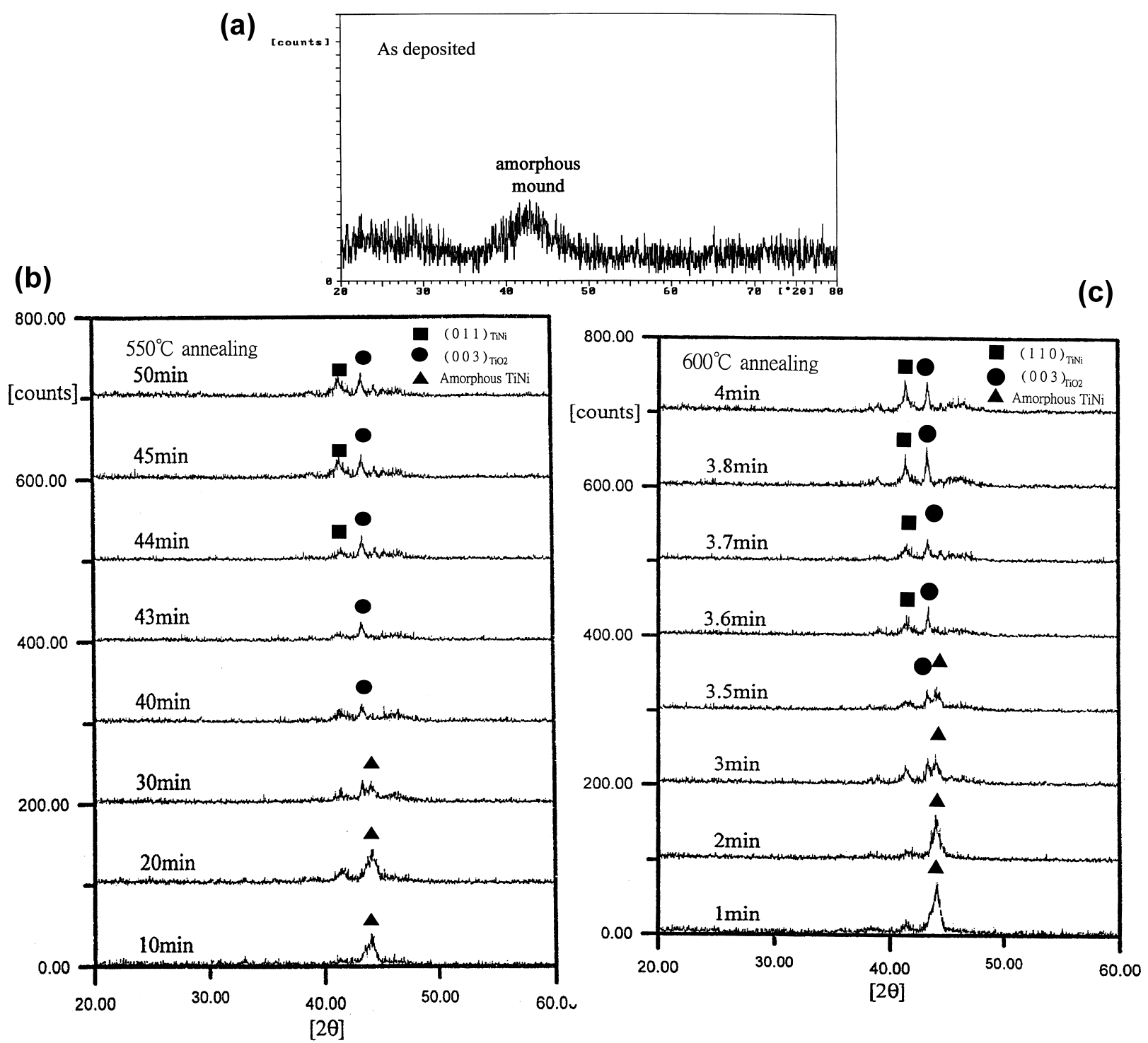

Fig. 9. XRD spectra of IR annealed film B: (a) as-deposited without annealing, (b) annealed at $550^{\circ} \mathrm{C}$ and (c) annealed at $600^{\circ} \mathrm{C}$ with various heating times. 
Table 4

Finishing time of crystallization versus isothermal annealing temperature for film B heated according to method IV in Table 2

\begin{tabular}{lllll}
\hline Crystallization temperature $\left({ }^{\circ} \mathrm{C}\right)$ & 550 & 575 & 600 & 625 \\
$\begin{array}{l}\text { Finishing time of crystallization } \\
\text { (min) }\end{array}$ & 44 & 14 & 3.7 & 1.4 \\
\hline
\end{tabular}

crystallization can be determined as $44 \mathrm{~min}$ and $3.7 \mathrm{~min}$ from Fig. 9b,c respectively. Similarly, the finish time of crystallization versus the other two annealing temperatures can also be determined by the same method and the results are shown in Table 4. From Table 4, the crystallization activation energy can be calculated by Eq. (3), but now $t_{0.5}$ is replaced by the finish time of crystallization. Fig. 10 shows the plots of $\ln \left(t_{\text {finish }}\right)$ against $1 / T$. From Fig. 10, the activation energy is estimated to be $287.6 \mathrm{~kJ} \mathrm{~mol}^{-1}$. This value is much lower than expected from the Buschow curve shown in Fig. 8.

From Section 3.2 and Section 3.3, the activation energy of film B estimated by XRD is obviously lower than that obtained by Kissinger's or Avrami's method. This characteristic may result from the effect of the Si substrate. It has been reported that deposited TiNi thin film on $\mathrm{Si}(100)$ wafer experiences compressive stress, and the amorphous-to-crystalline transformation tends to reduce the volume [17]. The stress relaxation during crystallization is measured to be about 50-100 MPa [17]. It seems reasonable that the inherently compressive stress on the TiNi thin film can enhance the crystallization because the crystallized TiNi thin film will reduce its volume and the compressive stress helps the crystallized volume to decrease. Hence the activation energy of the amorphous-to-crystalline transformation is expected to be lower in film B.

\section{Conclusion}

Amorphous thin films of $\mathrm{Ti}_{45.6} \mathrm{Ni}_{54.4}$ and $\mathrm{Ti}_{50.4} \mathrm{Ni}_{49.6}$ alloys were deposited onto (100)Si wafer by r.f. magnetron sputtering without heating the substrate. $\mathrm{Ti}_{45.6} \mathrm{Ni}_{54.4}$ thin films with thickness of $6-8 \mu \mathrm{m}$ were peeled from the substrate and the behavior of crystallization was studied using DSC. On the other hand, $\mathrm{Ti}_{50.4} \mathrm{Ni}_{49.6}$ thin films with a thickness of 1-2 $\mu \mathrm{m}$ were not removed from the substrate and their crystallization characteristics were studied by XRD. Experimental results show that the activation energy of an amorphousto-crystalline transformation of the $\mathrm{Ti}_{45.6} \mathrm{Ni}_{54.4}$ thin film is $385 \mathrm{~kJ} \mathrm{~mol}^{-1}$ by Avrami's method and $374 \mathrm{~kJ} \mathrm{~mol}^{-1}$ by Kissinger's method. The Avrami exponents are 2.56, 2.65, 2.7 , and 3 for annealing temperatures of 527, 532, 542, and $547^{\circ} \mathrm{C}$ respectively. The activation energy of $\mathrm{Ti}_{50.4} \mathrm{Ni}_{49.6}$ thin

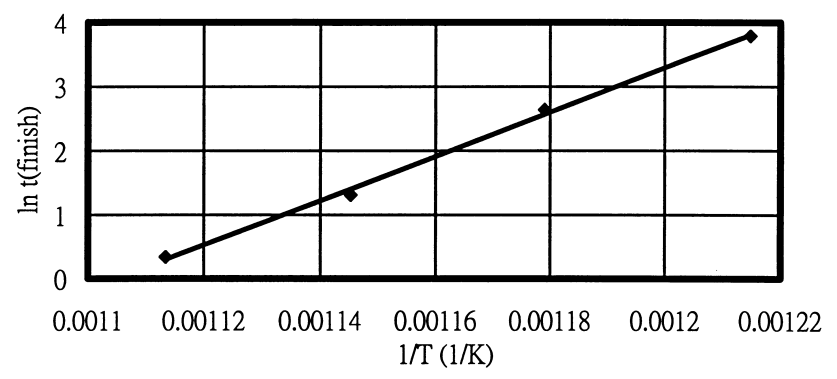

Fig. 10. Arrhenius plot for the finishing time of $100 \%$ crystallization versus 1/T from XRD data of Fig. 9 for film B.

film is estimated as $287.6 \mathrm{~kJ} \mathrm{~mol}^{-1}$, which is smaller than the values obtained by Avrami's and Kissinger's methods. The compressive stress induced between the TiNi thin film and (100)Si substrate and the volume reduction for the amorphous-to-crystalline transformation account for the decrease in activation energy of the $\mathrm{Ti}_{50.4} \mathrm{Ni}_{49.6}$ thin film.

\section{Acknowledgements}

The authors are grateful to financial support of this study by the National Science Council (NSC), Republic of China, under the Grant NSC86-2216-E002-015.

\section{References}

[1] C.M. Jackson, H.J. Wagner, R.J. Wasilewshki, NASA-sp5110, 1972.

[2] J.D. Busch, A.D. Johnson, C.H. Lee, D.A. Stevenson, J. Appl. Phys. 68 (1990) 6224.

[3] K.H. Buschow, J. Phys F: Met. Phys. 13 (1983) 563.

[4] M. Buchwitz, R. Adlwarth-Dieball, P.L. Ryder, Acta Metall. Mater. 41 (1993) 1885.

[5] C. Seeger, P.L. Ryder, Mater. Sci. Eng. A179/A180 (1994) 641.

[6] L. Hou, T.J. Pence, D.S. Grummon, Mater. Res. Soc. Symp. Proc. 360 (1995) 369.

[7] P. Krulevitch, A.P. Lee, P.B. Ramsey, J.C. Trevini, J. Hamilton, M.A. Northrup, J. Microelectromech. Syst 5 (1996) 270.

[8] E. Quandt, C. Halene, H. Holleck, K. Feit, P. Schlomacher, A. Skokan, K. D. Skrobanek, Sens. Actuators A53 (1996) 434.

[9] R.H. Wolf, A.H. Heuer, J. Microelectromech. Syst. 4 (1995) 206.

[10] H.E. Kissinger, Anal. Chem. 29 (1957) 1702.

[11] M. Avrami, J. Chem. Phys. 7 (1939) 1103.

[12] M. Avrami, J Chem. Phys. 8 (1940) 212.

[13] M. Avrami, J Chem. Phys. 9 (1941) 177.

[14] M.G. Scott, J. Mater. Sci. 13 (1978) 291.

[15] C.N.R. Rao, K. J. Rao, Phase Transitions in Solids, McGraw-Hill, 1978, p. 93.

[16] H. Fujita, M. Komatsu, T. Sakata, N. Fujita, Mater. Trans. JIM 37 (1996) 1350.

[17] J. Zhang, D.S. Grummon, Mater. Res. Soc. Symp. Proc. 450 (1997) 451 . 